\title{
Understanding of humping formation and suppression mechanisms using the numerical simulation
}

\author{
Dongsheng $\mathrm{Wu}^{1,2,3}$, Xueming Hua ${ }^{1,2}$, Dingjian $\mathrm{Ye}^{1,2}$, Fang $\mathrm{Li}^{1,2}$ \\ ${ }^{1}$ Shanghai Key Laboratory of Material Laser Processing and Modification(Shanghai Jiaotong University), Shanghai 200240, PR
}

China

${ }^{2}$ Collaborative Innovation Center for Advanced Ship and Deep-Sea Exploration, Shanghai, 200240, PR China

${ }^{3}$ Shanghai Power Equipment Research Institute, Shanghai, 200240, PR China

* Corresponding author. Tel.: +86 13661554311

E-mail address: xmhua@sjtu.edu.cn

\begin{abstract}
Three-dimensional numerical models are established to investigate the convection in normal and high speed GMAW processes. A high speed photography system is used to capture the transient images of the weld pool. Based on the simulation and experimental results, the differences of weld pool formation, convection and stability are researched. The humping formation mechanism in high speed GMAW process, and humping inhibition mechanism in the twin wire GMAW process are also discussed. The results show that in normal speed GMAW process, a clockwise circulation and a backward fluid flow pattern exist in the weld pool behind the arc. While in high speed GMAW process, three main factors are responsible for the humping formation: the high momentum of the backward fluid flow, the large variation of the capillary pressure of the liquid channel in the welding direction, and the capillary instability. The first two factors impede the backfilling of molten metal, and make the liquid channel susceptible to premature solidification, the final factor makes the weld pool unstable and susceptible to collapse. In the twin wire GMAW process, these factors are suppressed, in order to obtain sound weld bead, the trailing wire current should not be larger than the leading wire current.
\end{abstract}

Keywords: Weld pool convection; GMAW; Humping; Twin wire GMAW; FLOW3D

\section{Introduction}

Humping bead is a typical weld defect in high speed gas metal arc welding(GMAW) ${ }^{[1]}$, its occurrence limits the increasing of welding speed and the improvement of welding efficiency. Therefore, it is of great significance to study the formation of humping, and put forward methods to suppress it. 
Many kinds of models had been proposed to investigate the humping phenomenon. Based on experimental results, Bradstreet ${ }^{[2]}$ suggested that the instability caused by surface tension force was responsible for humping. Nguyen ${ }^{[1,3]}$ used a LaserStrobe video imaging system to obtain transient images of the weld pool during the formation of a hump, he proposed that the strong backward fluid flow caused by various forces was the major factor responsible for the initiation of humping. $\mathrm{Cho}^{[4]}$ used simulation and experimental methods to study the humping phenomenon, and pointed out that the thin liquid channel caused by elongation of the molten metal, and the premature solidification of thin liquid channel were the two requirements for humping formation. Chen ${ }^{[5]}$ developed a mathematic model to quantitatively analyze the formation mechanism of humping, the momentum and heat content of the backward flowing molten metal were considered. The humping formation in high speed laser welding and gas tungsten arc welding was also researched ${ }^{[6-9]}$. Many methods have been proposed to inhibit the formation of humping, such as laser +GMAW hybrid welding process ${ }^{[10-11]}$, DE-GMAW ${ }^{[12]}$, twin wire GMAW process ${ }^{[13]}$. An external magnetic field is exerted into the weld pool to suppress the humping ${ }^{[14-15]}$. Among these methods, the twin wire GMAW process is widely used in the industry for its low cost, high melting efficiency, low heat input, and sound weld seam quality ${ }^{[16]}$.

The fluid flow that influenced by droplet impinging momentum, electromagnetic force and surface tension is a key factor that influences the welding process and determines the final weld shape ${ }^{[17-18]}$. Sound weld bead can be obtained in normal speed GMAW process, humping appears in high speed GMAW process, but disappears in twin wire GMAW process. There are great differences of convection in these welding processes. In previous researches, investigations of humping phenomenon focused on the weld pool formation in high speed GMAW process, the differences of weld pool convection in normal and high speed GMAW processes, and twin wire GMAW process, are lack of researching. Deeper understanding of these differences is needed to study the humping and suppress it.

In this article, three-dimensional numerical models are established to investigate the convection in normal and high speed GMAW processes, the VOF method is utilized to trace the deformation of the free surface. The high speed photography system is used to capture the transient images of the weld pool. The differences of weld pool formation, convection and stability between normal and high speed GMAW processes are researched, the factors that influence the humping formation are analyzed. Based on prior work of the authors ${ }^{[13]}$, the humping suppression mechanism in the twin wire GMAW process will also be discussed.

\section{Experimental Procedure}

The experimental platform can be seen in Fig.1. Two (Panasonic) YD-500GR3 welders are used, materials selected for the welding experiments are 8mm-thick A36 steel and 1.2mm diameter of JM53 welding wire, thermo-physical material properties of A36 steel are shown in table1. In normal and high speed GMAW processes, the welding current is $280 \mathrm{~A}$, welding voltage is $30 \mathrm{~V}$, the welding speed is 
$0.5 \mathrm{~m} / \mathrm{min}$ and $1.5 \mathrm{~m} / \mathrm{min}$, respectively, $98 \% \mathrm{Ar}-2 \% \mathrm{CO}_{2}$ is used as shielding gas, the gas flow is $20 \mathrm{~L} / \mathrm{min}$, contact-tip-to-work-distance is $15 \mathrm{~mm}$. In twin wire GMAW process, the welding speed is $1.5 \mathrm{~m} / \mathrm{min}$, the distance between the two wires is $20 \mathrm{~mm}$. Two groups of different welding parameters are used in the experiment. In the first group, the welding parameters of leading wire and trailing wire are same, the welding current is $280 \mathrm{~A}$, the voltage is $30 \mathrm{~V}$. In the second group, the leading wire current is $250 \mathrm{~A}$, the voltage is $28 \mathrm{~V}$, the trailing wire current is $300 \mathrm{~A}$, the voltage is $33 \mathrm{~V}$.

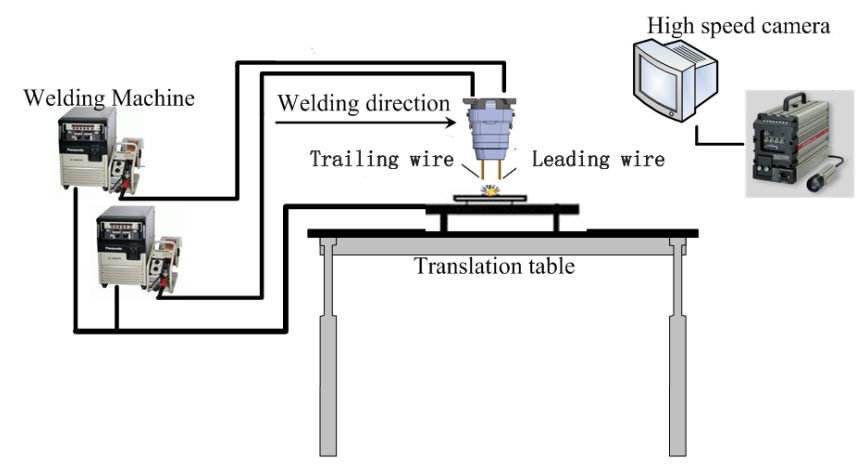

Fig.1 Diagram of the experimental platform.

During the welding experiments, images of the arc and the weld pool are captured by the high speed CCD camera with a $808 \pm 10 \mathrm{~nm}$ band pass filter. The band pass filter is used to filter out unwanted arc light, the frequency is one frame $/ 3 \mathrm{~ms}$. The transverse sections of the welds in normal and high speed GMAW processes are obtained after the experiments, and shown in Fig.2.

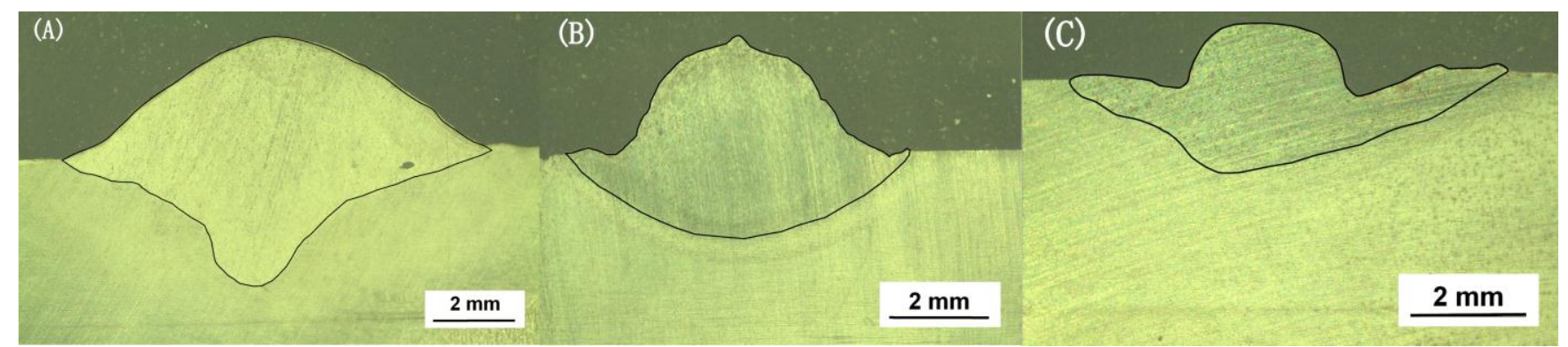

Fig.2 The transverse sections of the welds: (A) Normal speed GMAW process; (B) Hump in high speed GMAW process; (C)

Undercut in high speed GMAW process.

Table 1 Thermo-physical material properties of A36 steel used in simulation

\begin{tabular}{cccc}
\hline Nomenclature & Value & Nomenclature & Value \\
\hline Density & $7800\left(\mathrm{Kg} / \mathrm{m}^{3}\right)$ & Liquidus temperature & $1798(\mathrm{~K})$ \\
Viscosity & $6 \times 10^{-3}(\mathrm{Kg} / \mathrm{m} \cdot \mathrm{s})$ & Solidus temperature & $1768(\mathrm{~K})$ \\
Thermal conductivity(s) & $32.3(\mathrm{~W} / \mathrm{m} \cdot \mathrm{K})$ & Vaporized temperature & $2900(\mathrm{~K})$ \\
Thermal conductivity $(\mathrm{l})$ & $26(\mathrm{~W} / \mathrm{m} \cdot \mathrm{K})$ & Heat transfer coefficient & $100\left(\mathrm{~W} / \mathrm{m}^{2} \cdot \mathrm{K}\right)$ \\
Specific heat $(\mathrm{s})$ & $686(\mathrm{~J} / \mathrm{kg} \cdot \mathrm{K})$ & Emissivity & 0.5 \\
Specific heat $(\mathrm{l})$ & $866(\mathrm{~J} / \mathrm{kg} \cdot \mathrm{K})$ & Magnetic permeability & $1.26 \times 10^{-6}(\mathrm{H} / \mathrm{m})$ \\
\hline
\end{tabular}




\begin{tabular}{cccc} 
Latent heat of fusion & $2.77 \times 10^{5}(\mathrm{~J} / \mathrm{kg})$ & Coefficient of thermal expansion & $10^{-4}\left(\mathrm{~K}^{-1}\right)$ \\
Latent heat of vaporization & $7.34 \times 10^{6}(\mathrm{~J} / \mathrm{kg})$ & Surface tension & $1.2(\mathrm{~N} / \mathrm{m})$ \\
Environment temperature & $300(\mathrm{~K})$ & Surface tension gradient & -0.0003 \\
\hline
\end{tabular}

\section{Mathematical Model and Numerical Simulation}

Three-dimensional mathematic models are developed to study the weld pool convection in normal and high speed GMAW processes. The governing equations are solved using the FLOW3D software. The flow is laminar, the liquid metal is considered to be a Newtonian and incompressible fluid. The volume loss of liquid metal due to the metal evaporation is ignored. The droplets are modeled as a source term that carry mass, momentum and energy in the computational domain.

\subsection{Governing Equations}

The GMAW weld pools are modeled using 3D Cartesian coordinate system, the governing equations are mass, momentum, and energy equations. The free surface deformation of the weld pool can be traced using the VOF (Volume of Fluid) method ${ }^{[19]}$. Fluid configurations are defined in terms of volume function $\mathrm{F}(\mathrm{x}, \mathrm{y}, \mathrm{z}, \mathrm{t})$.

$$
\begin{aligned}
& \nabla \cdot \vec{V}=\frac{R_{S O R}}{\rho} \\
& \frac{\partial \vec{V}}{\partial t}+(\vec{V} \cdot \nabla) \vec{V}=-\frac{1}{\rho} \nabla P_{\mathrm{h}}+\mu \nabla^{2} \vec{V}+\mathrm{f}+\frac{R_{S O R}}{\rho} \cdot \vec{V}-K \vec{V} \\
& \rho\left(\frac{\partial h}{\partial t}+(\vec{V} \cdot \nabla) h\right)=\nabla(\kappa \nabla T)+R_{I S O R} \\
& \frac{\partial F}{\partial t}+\nabla(\vec{V} \cdot F)=F_{s}
\end{aligned}
$$

An additional advection relationship is used to expressed the convection of volume fraction in the fluid flow at the weld pool ${ }^{[19]}$. The energy source term $\mathrm{R}_{\text {ISOR }}$ can be calculated from the heat structure and fluid temperature.

$$
\begin{aligned}
& \frac{\partial \rho}{\partial t}+\nabla(\vec{V} . \rho)=R_{S O R} \\
& \rho=\rho_{0} F \\
& R_{S O R}=\rho_{0} F_{s} \\
& R_{I S O R}=h W_{A}\left(T_{w}-T\right)
\end{aligned}
$$




\subsection{Enthalpy-temperature relationship}

The energy-temperature relationship can be used to model the solid-liquid phase change. The fluid temperature in each cell can be determined from its enthalpy, the cell will become a part of mushy zone if the temperature is between liquidus and solidus temperature. The porous media drag concept can be used to model the flow in the mushy zone ${ }^{[19]}$.

$$
h=\left\{\begin{array}{lc}
\rho_{s} C_{s} T & \left(T \leq T_{s}\right) \\
h\left(T_{s}\right)+h_{s l} \frac{T-T_{s}}{T_{l}-T_{s}} & \left(T_{s}<T \leq T_{l}\right) \\
h\left(T_{l}\right)+\rho_{l} C_{l}\left(T-T_{l}\right) & \left(T_{l}<T\right)
\end{array}\right.
$$

\subsection{Heat source model}

In normal speed GMAW process, the heat input from the arc is modeled as Gaussian distribution, the Gaussian heat distribution parameter can be calculated from the empirical equation ${ }^{[19]}$.

$$
\begin{aligned}
& q(x, y)=\frac{\eta \mathrm{Q}}{2 \pi \sigma_{a}^{2}} \exp \left(\frac{-x^{2}-y^{2}}{2 \sigma_{a}^{2}}\right) \\
& \sigma_{a}=0.533 \mathrm{I}^{0.2941}
\end{aligned}
$$

In high speed GMAW process, even though the arc heat input is also Gaussian distributed, but the calculated Gaussian heat distribution parameter is divided by 2, and the arc heat input acted on the material outside of $3.28 \mathrm{~mm}$ radius (measured from experimental weld as the half width of the gouged region) is zero $^{[4]}$.

\subsection{Body forces}

The body forces in the weld pool include electromagnetic force and buoyancy. The Boussinesq approximation can be used to model the buoyancy of the liquid metal ${ }^{[19]}$.

The electromagnetic force is calculated based on the current flow and magnetic field in the weld pool $^{[20]}$ :

$$
\begin{aligned}
& J_{r}=-\sigma_{e} \frac{\partial \phi}{\partial r} ; J_{z}=-\sigma_{e} \frac{\partial \phi}{\partial z} \\
& B_{\theta}=\frac{\mu_{0}}{r} \int_{0}^{r} J_{z} r d r
\end{aligned}
$$

Where $\phi$ is the scalar electric potential, which satisfies the Maxwell equation ${ }^{[20]}$.

\subsection{Arc pressure}

In normal speed GMAW process, the arc pressure act on the free surface of the weld pool can be approximated as Gaussian density distribution ${ }^{[19]}$, the total pressure and the Gaussian pressure distribution parameter are functions of current and electrode tip angle. 


$$
\begin{aligned}
& P_{\text {arc }}=\frac{P}{2 \pi \sigma_{P}^{2}} \exp \left(-\frac{\mathrm{x}^{2}+y^{2}}{2 \sigma_{P}^{2}}\right) \\
& P= \begin{cases}-0.04017+0.0002553 \cdot I(N) & \left(60^{\circ} \text { tip angle }\right) \\
-0.04307+0.0001981 \cdot I(N) & \left(90^{\circ} \text { tip angle }\right)\end{cases} \\
& \sigma_{P}= \begin{cases}1.4875+0.00123 \cdot I(\mathrm{~mm}) & \left(60^{\circ} \text { tip angle }\right) \\
1.4043+0.00174 \cdot I(\mathrm{~mm}) & \left(90^{\circ} \text { tip angle }\right)\end{cases}
\end{aligned}
$$

In high speed GMAW process, the total pressure and the Gaussian pressure distribution parameter can be expressed as the following expressions, the calculated Gaussian pressure distribution parameter is divided by $2^{[4]}$.

$$
\begin{aligned}
& \mathrm{P}=0.000176398 . \mathrm{I}+0.0123291925 . \mathrm{I}(\mathrm{N}) \\
& \sigma_{P}=1.4875+0.00123 . \mathrm{I}(\mathrm{mm})
\end{aligned}
$$

\subsection{Surface tension force}

The surface tension of the liquid metal is simplified as a linear function of temperature:

$$
\gamma=\gamma_{0}-A\left(T-T_{m}\right)
$$

\subsection{Drop generation}

The droplets are modeled as a source term that carry mass, momentum and energy in the computational domain. According to the literatures, the droplets are assumed to be spherical shape with radius $0.5 \mathrm{~mm}$, initial velocity $0.5 \mathrm{~m} / \mathrm{s}$ in the negative $\mathrm{z}$ direction, and transfer frequency $400 \mathrm{drops} / \mathrm{s}^{[21]}$. The temperature of the droplets is set to be $2800 \mathrm{~K}^{[4]}$ 。

\subsection{Boundary Conditions}

The boundary conditions of the computational domain for the governing equations include energy and momentum boundary conditions.

\subsubsection{Energy boundary conditions}

For the top free surface, convection, radiation and evaporation are considered:

$$
\begin{aligned}
& \kappa \frac{\partial T}{\partial \vec{n}}=q(x, y)-q_{c o n v}-q_{\text {rad }}-q_{\text {evap }} \\
& q_{\text {conv }}=h_{c}\left(T-T_{0}\right) \\
& q_{\text {rad }}=\sigma \varepsilon\left(T^{4}-T_{0}^{4}\right) \\
& q_{\text {evap }}=m_{e} M_{b}
\end{aligned}
$$




$$
\log \left(m_{e}\right)=A_{v}+\left(6.121-\frac{18836}{T}\right)-0.5 \log T
$$

For other surface:

$\kappa \frac{\partial T}{\partial \vec{n}}=-h_{c}\left(T-T_{0}\right)-\sigma \varepsilon\left(T^{4}-T_{0}^{4}\right)$

\subsubsection{Momentum boundary conditions}

To model Marangoni convection, surface tension gradient on the top free surface should be equal to the shear stress:

$$
\begin{aligned}
& \mu \frac{\partial u}{\partial z}=-\frac{\partial \gamma}{\partial T} \frac{\partial T}{\partial x} \\
& \mu \frac{\partial v}{\partial z}=-\frac{\partial \gamma}{\partial T} \frac{\partial T}{\partial y}
\end{aligned}
$$

Other surface: $u=v=w=0$

The normal pressure balance of the top free surface is expressed as:

$$
-p+2 \mu \frac{\partial \overrightarrow{v_{n}}}{\partial \vec{n}}=-p_{\text {arc }}+\gamma\left(\frac{1}{R_{1}}+\frac{1}{R_{2}}\right)
$$

\begin{tabular}{|c|c|c|c|}
\hline Symbol & Nomenclature & Symbol & Nomenclature \\
\hline$\vec{V}$ & Velocity vector & $\beta$ & Coefficient of volume expansion \\
\hline $\mathrm{R}_{\text {SOR }}$ & Mass source term & $\sigma_{\mathrm{p}}$ & Gaussian pressure distribution parameter \\
\hline$\rho$ & Zone density at current cell & $\gamma$ & Surface tension \\
\hline$\rho_{0}$ & Density of material & $\gamma_{0}$ & The surface tension of pure metal at the melting point \\
\hline $\mathrm{p}_{\mathrm{h}}$ & Hydrodynamic pressure & A & The negative of surface tension gradient for pure metal \\
\hline$\mu$ & Kinematic viscosity & $\eta$ & Arc efficiency \\
\hline $\mathrm{f}$ & Acceleration due to body force & U,I & Welding voltage and current \\
\hline $\mathrm{K}$ & Drag coefficient & $\sigma_{\mathrm{a}}$ & Gaussian heat distribution parameter \\
\hline $\mathrm{h}$ & Internal energy per unit mass & $\mathrm{J}_{\mathrm{r}}, \mathrm{J}_{\mathrm{Z}}$ & Radial and axial current density \\
\hline к & Thermal conductivity & $\mathrm{B}_{\theta}$ & Self-induced magnetic field \\
\hline $\mathrm{R}_{\text {ISOR }}$ & Energy source term & $\mathrm{h}_{\mathrm{c}}$ & Heat transfer coefficient \\
\hline $\mathrm{T}$ & Temperature & $\sigma$ & Boltzmann constant \\
\hline $\mathrm{T}_{\mathrm{w}}$ & Heat structure surface temperature & $\varepsilon$ & Emissivity \\
\hline $\mathrm{A}_{\mathrm{w}}$ & Heat structure surface area & $\mathrm{m}_{\mathrm{e}}$ & Evaporation Rate \\
\hline Ts, $\mathrm{T}_{1}$ & Solidus and liquidus temperature & $\mathrm{M}_{\mathrm{b}}$ & Latent heat of vaporization \\
\hline $\mathrm{T}_{\mathrm{o}}$ & Environment temperature & $A_{v}$ & Constant \\
\hline
\end{tabular}

Table 2 Simulation parameters 


\begin{tabular}{cccc}
$\mathrm{F}$ & $\begin{array}{c}\text { Volume fraction of fluid } \\
\text { The change of the volume fraction } \\
\text { of fluid }\end{array}$ & $\vec{n}$ & The velocity in $\mathrm{x}$ y z direction \\
$\mathrm{F}_{\mathrm{s}}$ & $\begin{array}{c}\text { Solid and liquid density } \\
\rho_{\mathrm{s}}, \rho_{1}\end{array}$ & $\overline{\mathrm{v}}_{\mathrm{n}}$ & Normal to the free surface \\
$\mathrm{C}_{\mathrm{s}}, \mathrm{C}_{1}$ & $\begin{array}{c}\text { Specific heat of the solid and } \\
\text { liquid phases }\end{array}$ & $\mathrm{P}_{\mathrm{arc}}$ & normal velocity vector \\
$\mathrm{h}_{\mathrm{sl}}$ & Latent heat of fusion & $\mathrm{R}_{1}, \mathrm{R}_{2}$ & Pressure \\
\hline
\end{tabular}

\subsection{Numerical Method}

Due to the symmetry, half of the base metal is used in the computational domain. Finite volume method is applied to discrete the governing equations, the whole computational domain is meshed with $0.25 \mathrm{~mm}$ cubical cells, time step is set to be $2.3 \times 10^{-5} \mathrm{~s}$. The governing equations and VOF equation with the required boundary conditions are numerically solved through the following three steps:

(1) The explicit method is used to update the velocities at the present time.

(2) The SOR method is used to solve the pressure correction formula, the mass conservation equation is satisfied, the implicit method is used to solve the energy conservation equation.

(3) The VOF equation is used to update the configuration of the free surface.

\section{Results and Discussion}

The simulations of normal and high speed GMAW processes are conducted, the detail results are analyzed.

\subsection{Weld pool formation}

Under the effect of arc heat and enthalpy of droplets, the base metal begins to melt and the weld pool forms. The free surface of the pool is depressed by the high drop momentum, arc pressure and electromagnetic force. In normal speed GMAW process, as shown in Fig.3, the red parts of the temperature fields indicate that the temperature of the metal is high than the melting point. The pool penetration, width and weld reinforcement are developed gradually as welding time increases, and do not change much after $4.3 \mathrm{~s}$, the welding process reaches quasi-steady state. Although a big weld reinforcement forms behind the arc, but it does not accumulate and grow up. The similar results can be seen in high speed photographs of Fig.4. 


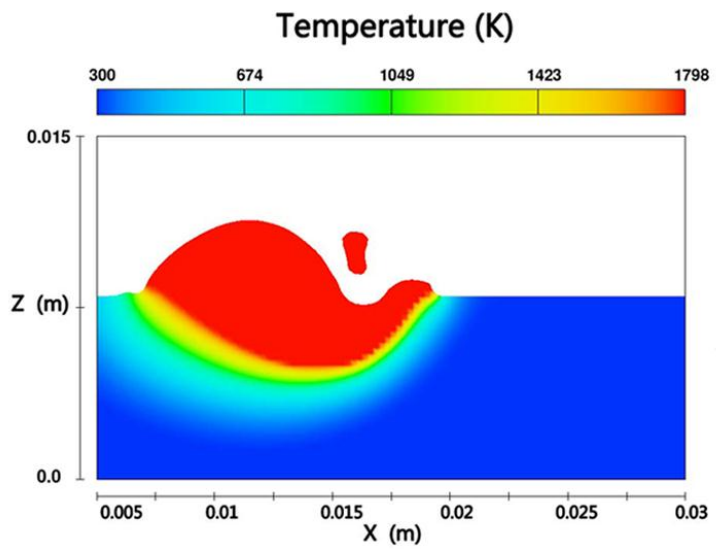

(A)

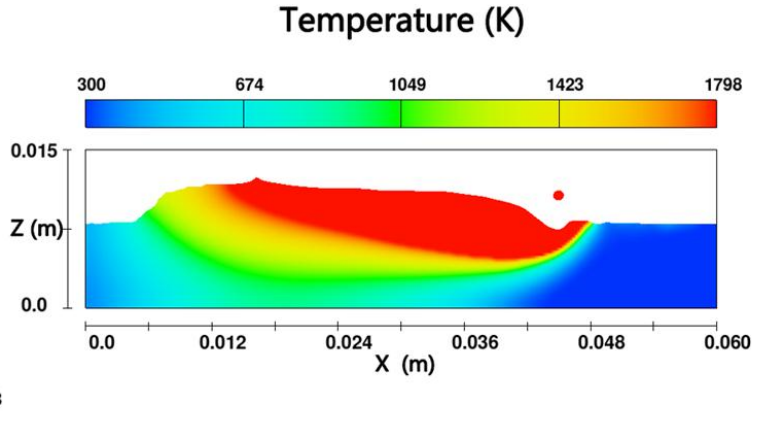

(B)

Fig. 3 The temperature (K) fields of $y=0$ longitudinal cross sectional view in normal speed GMAW process: (A) $0.3 \mathrm{~s}$; (B) $4.3 \mathrm{~s}$.

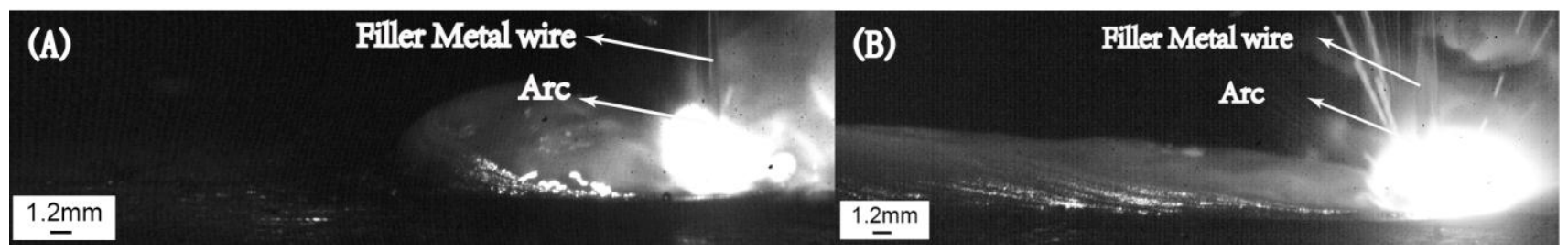

Fig.4 The high speed photographs of the weld pool in normal speed GMAW process: (A) 0.3s; (B)4.3s.

In high speed GMAW process, as shown in Fig.5 and Fig.6, at $\mathrm{t}=0.3 \mathrm{~s}$, under the influence of high drop momentum, arc pressure and electromagnetic force, a deep narrow penetrated region ("gouged" region) appears and does not disappear in the whole welding process. The "gouged" region has a significant effect on the formation of humping, which will be discussed in subsequent paragraph. The droplets, molten base metals and the thin layer located under the arc merge behind the arc, to form a combined stream of molten metal, the molten metal flows to the back of the weld pool. With more and more molten metal accumulated at the trailing of the weld pool, the swelling forms. At $t=1 \mathrm{~s}$, as the welding arc moves, the size of the swelling is increasing, the liquid channel that connects the front part of the weld pool becomes elongated. When the liquid channel is far from the arc, the molten metal inside the liquid channel can't get enough arc heat, making it vulnerable to rapid solidification. At $\mathrm{t}=1.35 \mathrm{~s}$, the premature solidification of the melt in the liquid channel signals the formation of valley, and the completion of one hump. The solidified valley can prevent the flow of the molten metal to the swelling. At $t=2 s$, the solidification of the swelling, the initiation and growth of a new swelling will occur. 


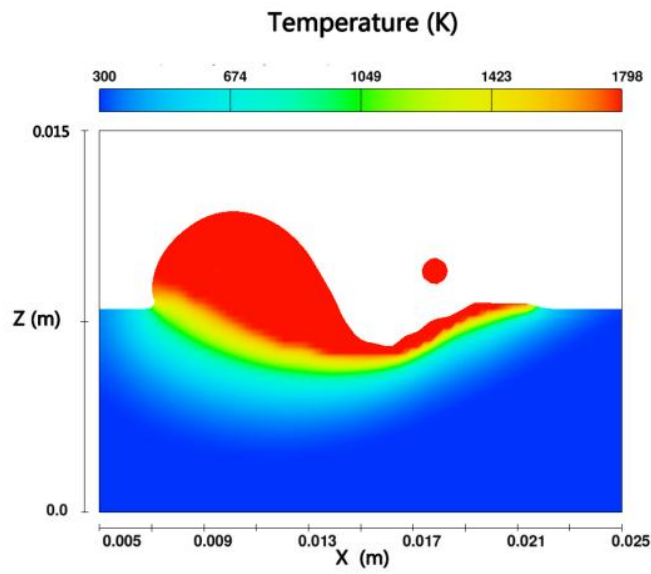

(A)

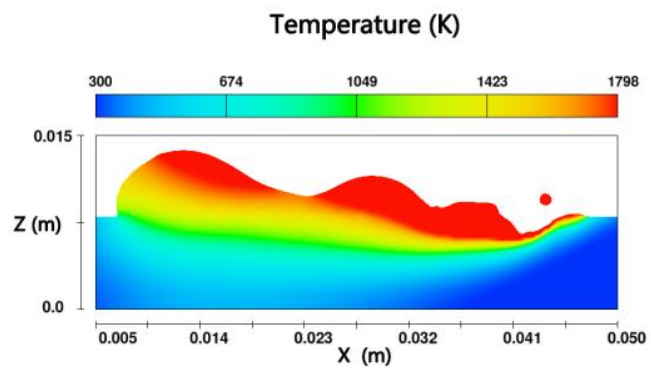

(C)

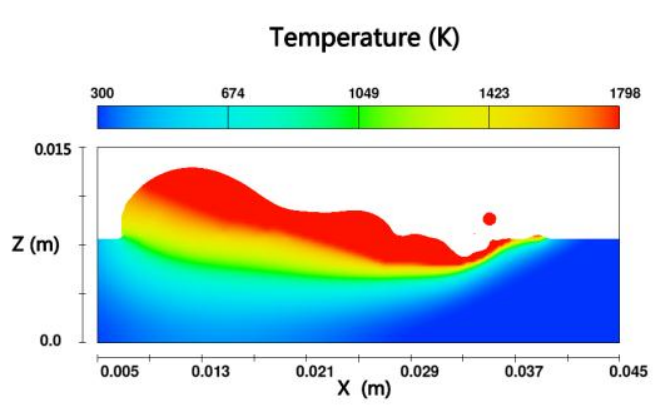

(B)

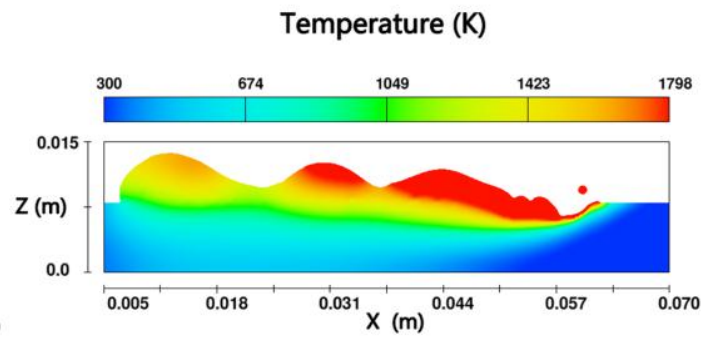

(D)

Fig.5 The temperature (K) fields of $y=0$ longitudinal cross sectional view in high speed GMAW process: (A) 0.3s; (B)1s; (C) $1.35 \mathrm{~s} ;$ (D)2s.

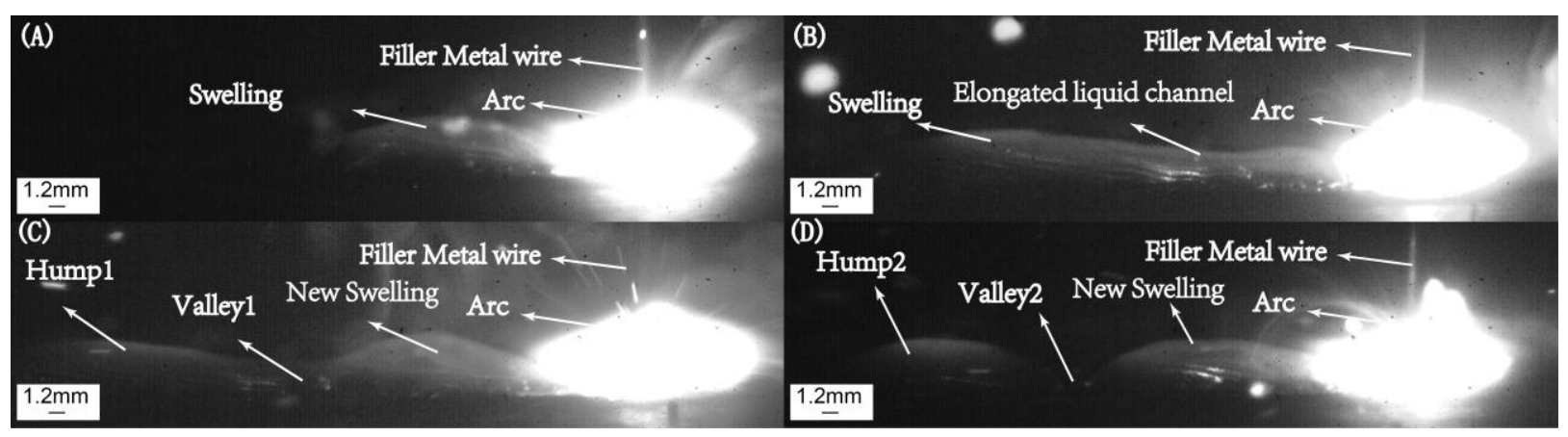

Fig.6 The high speed photographs of $y=0$ longitudinal cross sectional view in high speed GMAW process: (A) 0.3s; (B)1s;

$$
\text { (C) } 1.35 \mathrm{~s} ;(\mathrm{D}) 2 \mathrm{~s} \text {. }
$$

\subsection{Weld pool convection}

As discussed above, there are huge differences in the weld pool formation between the normal and high speed GMAW processes, investigation of the weld pool convection can help us better understand these differences. As shown in Fig.7(A), in normal speed GMAW process, the large molten metal under the arc can absorb and dissipate the momentum of the droplets, while in high speed GMAW process, As shown in Fig.7(B), the steep leading edge of the gouged region can effectively change the downward momentum of droplets to the back of the weld pool, and increase the velocity of the backward fluid flow. Besides, the gouged region can impede the wetting of molten metal, few molten metal fills the penetration ${ }^{[4]}$. The higher 
momentum of the backward fluid flow in high speed GMAW process is responsible for the initiation and growth of the swelling. The surface tension has a great influence on the shape of the weld bead ${ }^{[1]}$. It can also be seen from Fig.7(B) that the temperature of the molten metal within the swelling is lower than that at the front part of the weld pool. Since the surface tension temperature coefficient is negative, the molten metal within the swelling has a high surface tension, which also contributes to growth of the swelling. If the surface tension is low, the molten metal within the swelling will flatten out onto the surface of the base metal.

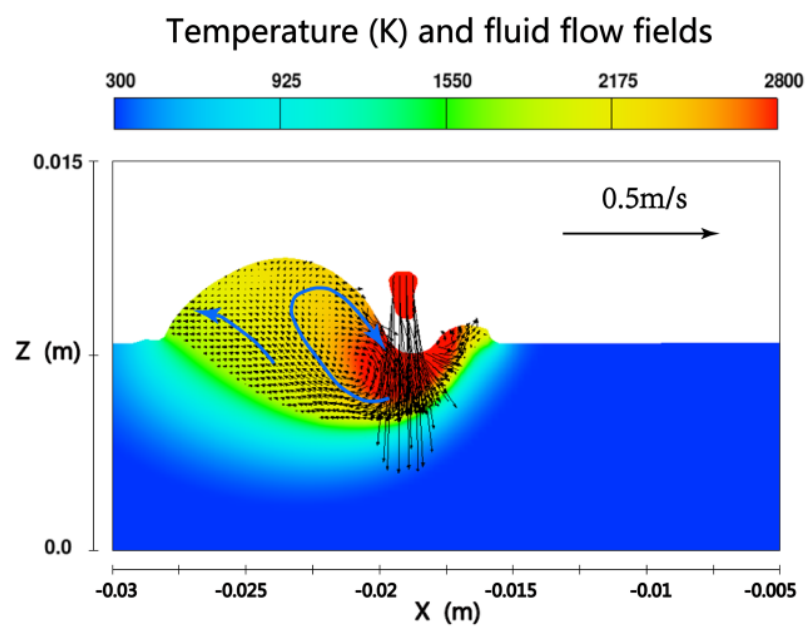

(A)

\section{Temperature $(K)$ and fluid flow fields}

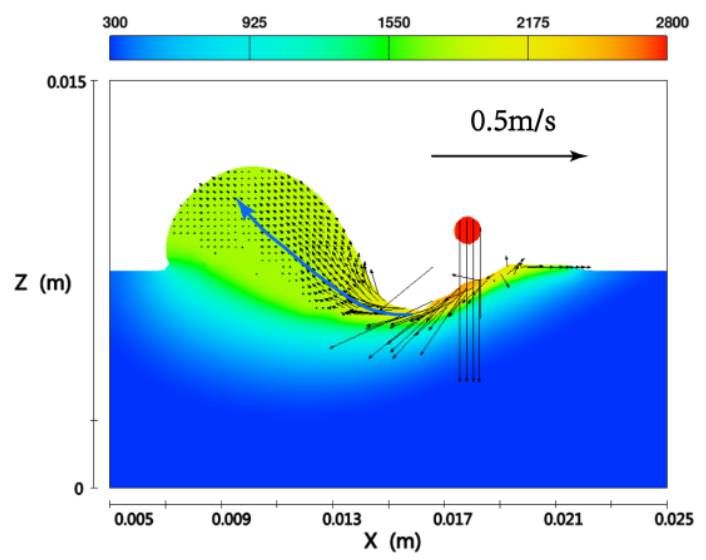

(B)

Fig.7 The temperature $(K)$ and fluid flow fields of $y=0$ longitudinal cross sectional view at $t=0.3 \mathrm{~s}$ : (A) Normal speed GMAW process; (B) High speed GMAW process.

As shown in Fig.7(A), in normal speed GMAW process, under the combined effect of droplets momentum, arc pressure, electromagnetic force and surface tension, a clockwise circulation and a backward fluid flow pattern exist in the weld pool behind the arc, the weld reinforcement is limited by the recirculation of molten metal towards the front of the weld pool, so the accumulation of molten metal in the trailing of the weld pool does not occur. It can be seen from Fig.8 that the flow pattern does not change as welding time increases, the convection in the weld pool is stable.

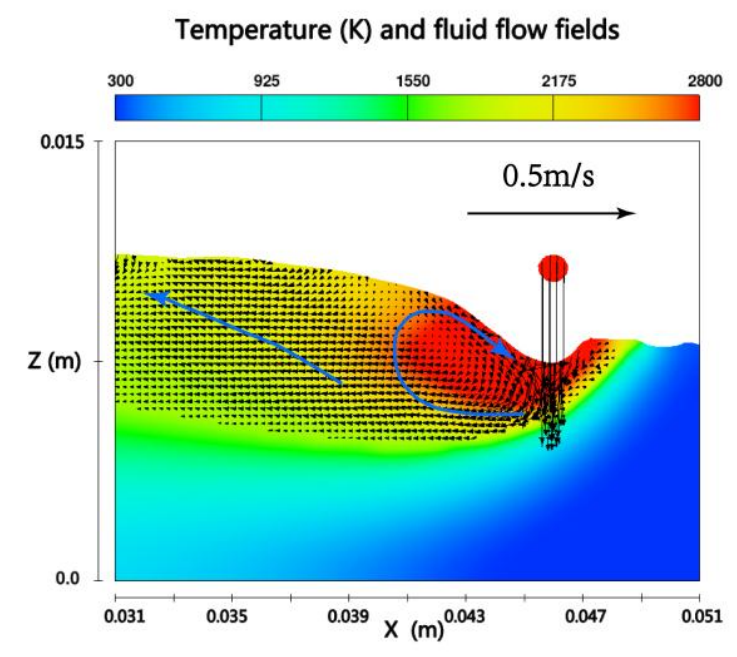


Fig. 8 The temperature $(\mathrm{K})$ and fluid flow fields of $\mathrm{y}=0$ longitudinal cross sectional view in normal speed GMAW process at $\mathrm{t}=4.3 \mathrm{~s}$.

It can be seen from Fig.9(A) that the difference of weld width in the welding direction is small, as the capillary pressure is proportional to the curvature in a cylindrical section, so in normal speed GMAW process, the variation of the capillary pressure of the liquid channel in the welding direction is small. As shown in Fig.9(B), the surface tension at the pool center is lower than that near the pool edge, the liquid metal driven by the surface tension flows from the pool center to the pool edge. This outward flow pattern contributes to the small variation of the weld width.

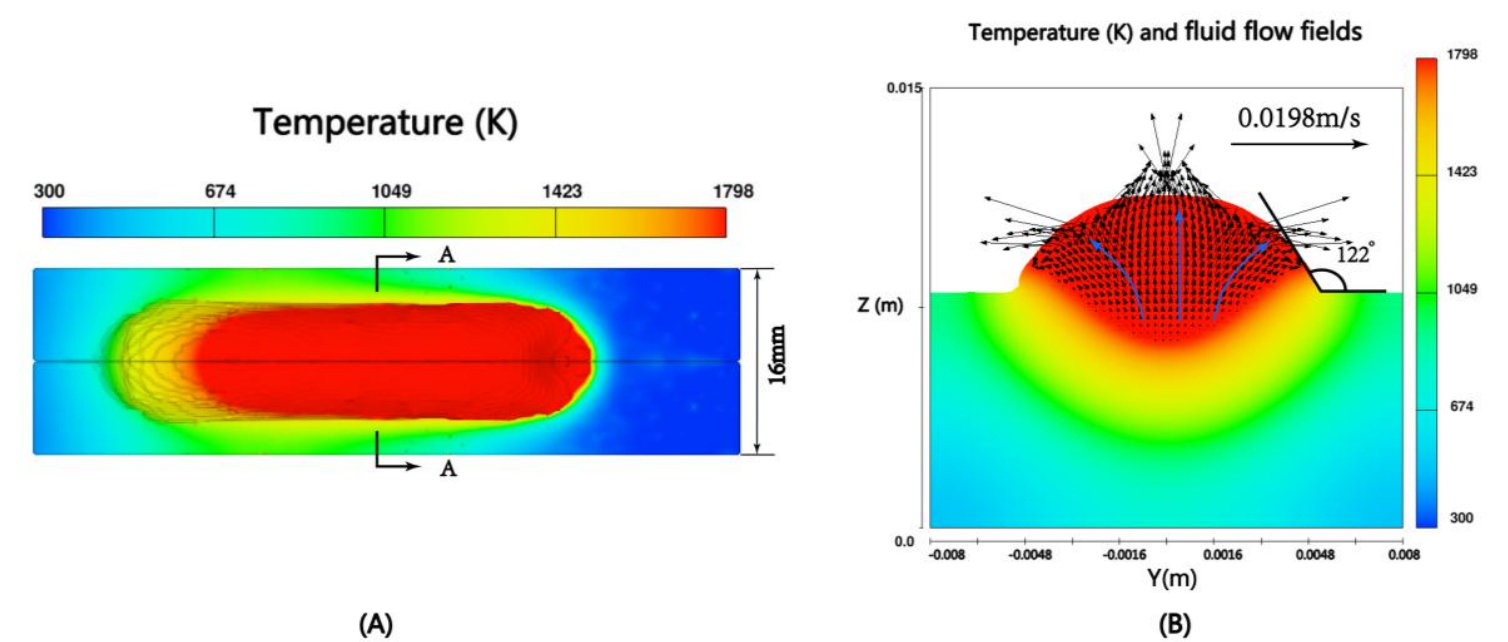

Fig.9 (A)The top view of the weld pool in normal speed GMAW process at $\mathrm{t}=4.3 \mathrm{~s}$; (B) The temperature (K) and fluid flow fields of A-A section.

In high speed GMAW process, As shown in Fig.7(B) and Fig.10, the flow pattern in high speed GMAW weld pool does not change as welding time increases. Even though the molten metal flows to the back of the weld pool, but the backfilling of the front part of the weld pool does not happen, so the size of the swelling is increasing, the liquid channel is elongated as welding time increases. As more and more molten metal accumulated at the trailing of the weld pool, the volume of molten metal in the liquid channel is decreased. It can be seen from Fig.11 that the weld width decreases in the welding direction, due to the variation of transverse curvature along the liquid channel, the capillary pressure of the liquid channel at the front part of the weld pool is larger than that at the back of the weld pool. The variation of the capillary pressure of the liquid channel in the welding direction can promote the shrinkage of liquid channel, thus the exchange of molten metal between front part and trailing part of the weld pool is slow. Besides, due to the heat loss, the temperature of the molten metal in the liquid channel declines, leading to the poor fluidity of the melt, all of these reasons contribute to the liquid channel having the tendency of premature solidification. Then the neck of liquid channel solidifies, it is a necessary step for the hump formation, it indicates the formation of the valley which divides the weld pool into two portions. As shown in Fig.12, the convection in the front portion is driven by droplets momentum, arc pressure, electromagnetic force and surface tension force, the similar process of hump formation will repeat in the front portion of the weld pool. It is worth 
mentioning that thermocapillary force plays a minor role in hump formation ${ }^{[22]}$. Based on numerical results, Cho also concluded that the thermocapillary (Marangoni) flow had small influence on hump formation ${ }^{[4]}$. Temperature $(\mathrm{K})$ and fluid flow fields

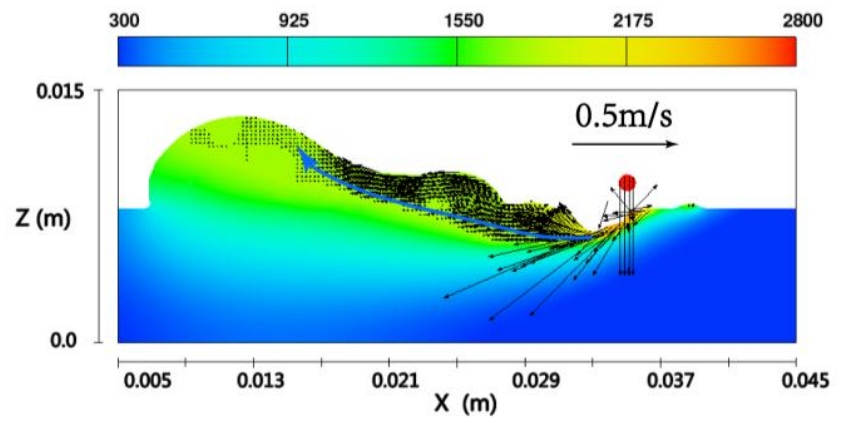

Fig.10 The temperature $(\mathrm{K})$ and fluid flow fields of $\mathrm{y}=0$ longitudinal cross sectional view in high speed GMAW process at $\mathrm{t}=1 \mathrm{~s}$

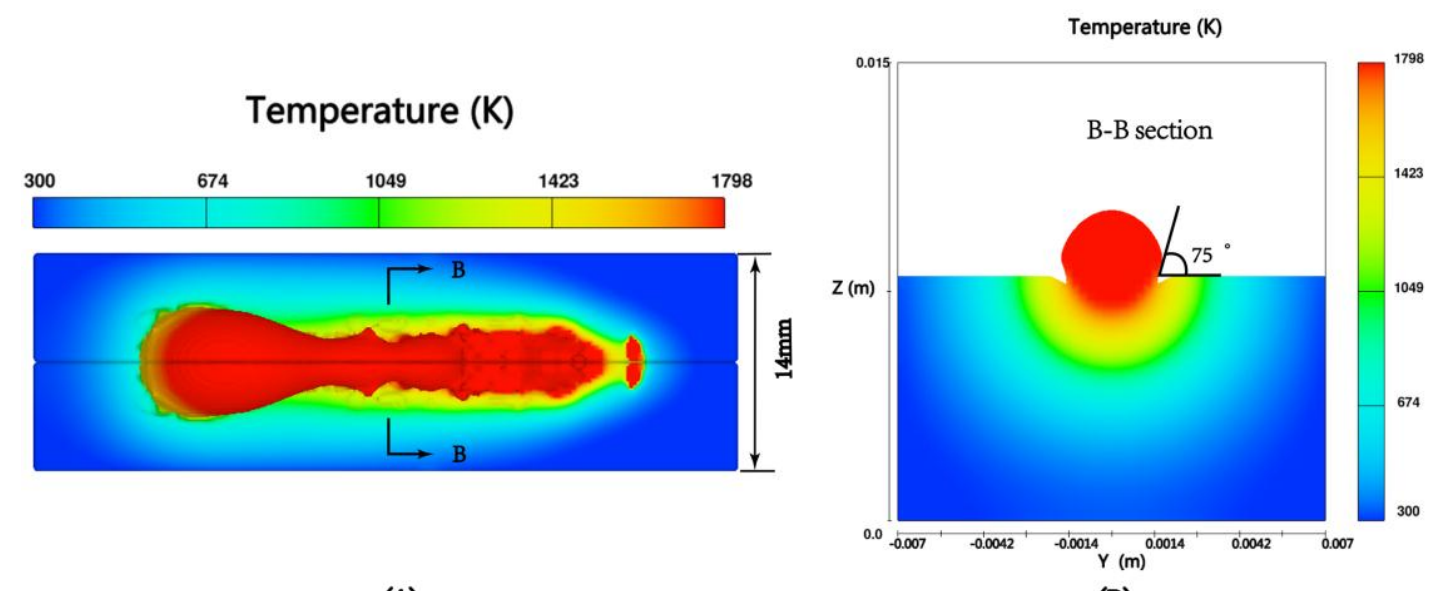

(A)

(B)

Fig.11 (A)The top view of the weld pool at $\mathrm{t}=1 \mathrm{~s}$; (B) B-B section of the weld pool.

Temperature $(K)$ and fluid flow fields

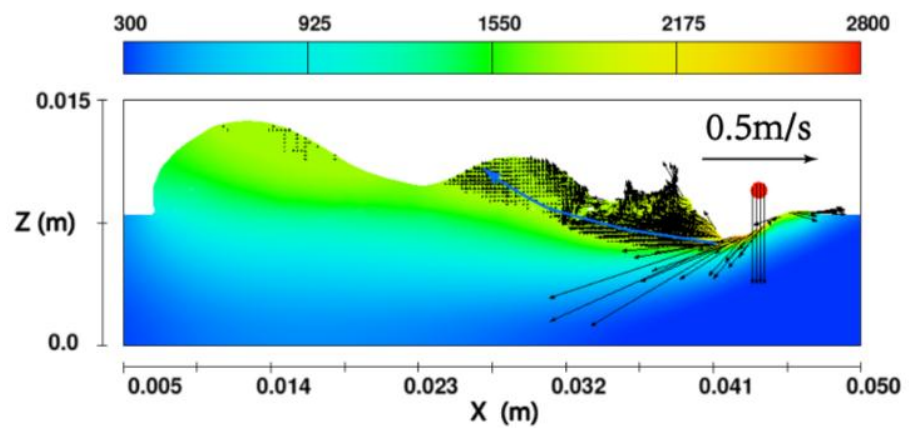

Fig.12 The temperature $(\mathrm{K})$ and fluid flow fields of $\mathrm{y}=0$ longitudinal cross sectional view at $\mathrm{t}=1.35 \mathrm{~s}$.

\subsection{Instabilities related to humping}

Capillary instability has an important effect on the humping formation ${ }^{[4]}$. When the contact line is arrested, the internally measured contact angle determines the stability of the weld pool. In normal speed GMAW process, as shown in Fig.9(B), the external contact angle is $122^{0}$, the internal contact angle is $58^{0}$, 
the weld pool is stable. In high speed GMAW process, as shown in Fig.11(B), the external contact angle at the neck of the liquid channel is $75^{\circ}$, the internal contact angle is $105^{\circ}$, the weld pool is unstable and susceptible to collapse. In the previous investigation by Gratzke et al ${ }^{[22]}$, it was noted that humping will be occurred when the width/length ratio of the weld pool was less than about 0.1 . The width/length ratio in normal speed GMAW process is 0.31 , and 0.085 at the neck of the liquid channel in high speed GMAW process.

\subsection{Formation mechanism of humping}

As discussed above, three main factors are responsible to the humping formation. The first factor is the high momentum of the backward fluid flow, which causes the initiation and growth of swelling, for the amount of filler metal is limited, the amount of molten metal and energy in the liquid channel is few. The second factor is the large variation of the capillary pressure of the liquid channel in the welding direction, which can promote the shrinkage of liquid channel. These two factors impede the backfilling of molten metal, and make the liquid channel susceptible to premature solidification. The final factor is the capillary instability, making the weld pool unstable and susceptible to collapse.

\subsection{Suppression mechanism of humping}

Two groups of different welding parameters are used in the twin wire GMAW process. In the first group, the welding parameters of leading wire and trailing wire are same, it can be seen from Fig.13(A) that two swellings form behind the leading and trailing wires at the beginning of the twin wire GMAW process, the sizes of the swellings are increasing with the welding arc moves. Two separate weld pools connect to form one pool at $\mathrm{t}=0.78 \mathrm{~s}$. As the welding time increases, the welding process reaches quasi-steady state, a bulge forms between the leading and trailing wires, but the swelling at the back of the weld pool disappears. As shown in Fig.13(B), the width of the weld bead is uniform, the humping disappears in twin wire GMAW process.

(A)

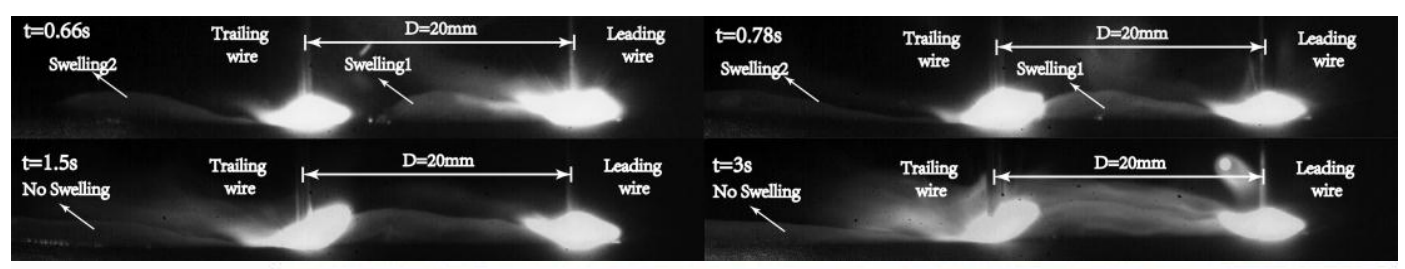

(B)

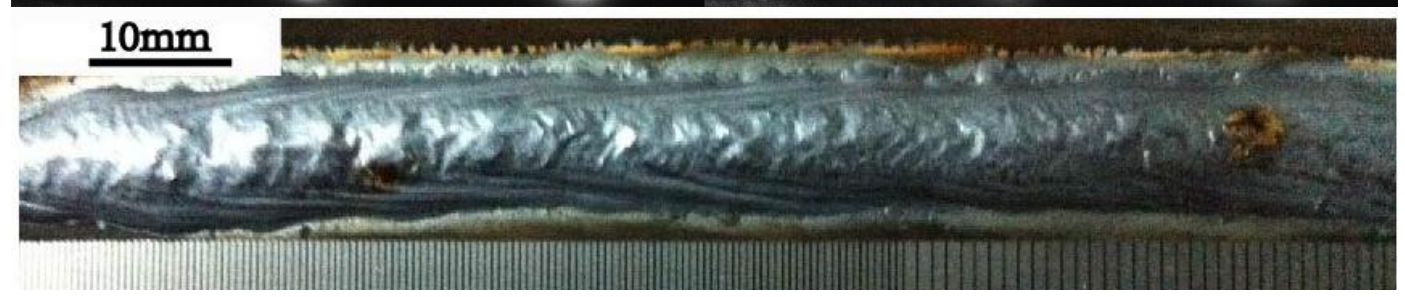

Fig.13 (A) High speed photographs of the weld pool in twin wire GMAW process, the welding parameters of leading wire and trailing wire are same; (B) Top view of the final weld bead.

Based on prior work of the authors ${ }^{[14]}$, diagram of weld pool convection in twin wire GMAW process is 
presented in Fig.14.

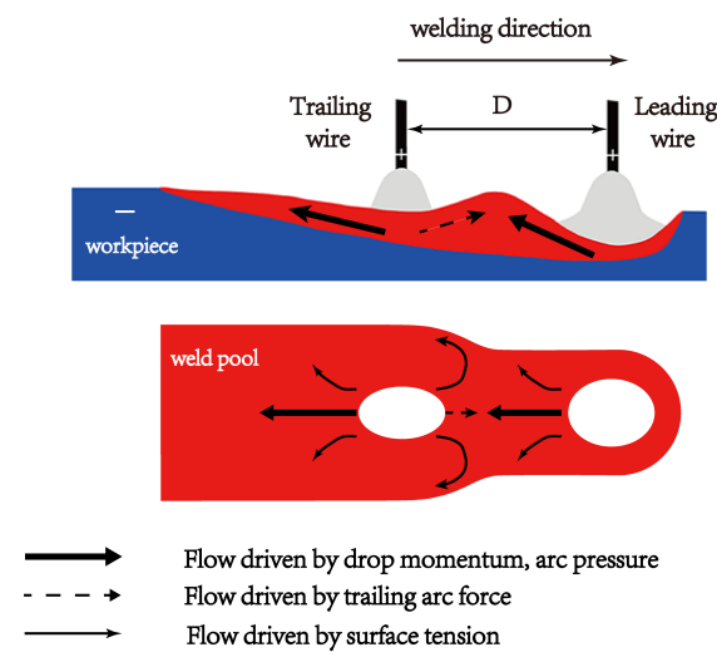

Fig.14 Diagram of weld pool convection in twin wire GMAW process

When two separate weld pools connect to form one pool, the convection in the weld pool changes. Due to the "push-pull" way exists in the twin wire GMAW weld pool, the liquid metal driven backward by the leading wire arc pressure is suppressed by the trailing wire arc pressure, thus a bulge forms between the two wires. Due to the backward component of the trailing wire arc pressure is reduced, the momentum of the backward fluid flow is slow, so no swelling forms at the back of the weld pool.

The volume of deposited metals in twin wire GMAW process is twice of that in high speed GMAW process. For the volume of the bulge between the two wires is almost unchanged at quasi-steady state, more molten metals and energy can be transferred to the liquid channel behind the trailing wire. Besides, the outward flow pattern caused by the surface tension gradient exists in the weld pool, all of these reasons contribute to the small variation of weld width, so the variation of the capillary pressure of the liquid channel in the welding direction is small. The weld pool is stable. In summary, the low momentum of the backward fluid flow, the small variation of the capillary pressure of the liquid channel in the welding direction, and the capillary stability contribute to the disappearance of humping in twin wire GMAW process.

\subsection{The influence of current ratio on weld bead formation}

In the second group, the trailing wire current is larger than the leading wire current, the total heat input is similar to that in the first group. It can be seen from Fig.15(A) that the humping is suppressed, but the weld width is uneven in the welding direction. As shown in Fig.15(B), the swelling behind the trailing wire is larger than that behind the leading wire at $\mathrm{t}=0.66 \mathrm{~s}$. Two separate weld pools connect to form one pool at $\mathrm{t}=0.78 \mathrm{~s}$. Due to the "push-pull" way exists in the weld pool, the momentum of the backward fluid flow is reduced, which is help to suppress the formation of humping. However, the arc pressure of the trailing wire is larger than that of the leading wire, few molten metal and energy can be transferred to the liquid channel behind the trailing wire, a large bulge forms behind the two wires, as shown in the high speed images at 
$\mathrm{t}=1.14 \mathrm{~s}$. It can also be seen from Fig.15(B) that a small bulge periodically appears behind the trailing wire , which causes the periodic change of the volume of the molten metal that transferred to the back of weld pool, so the weld width along the welding direction is not uniform.

(A)

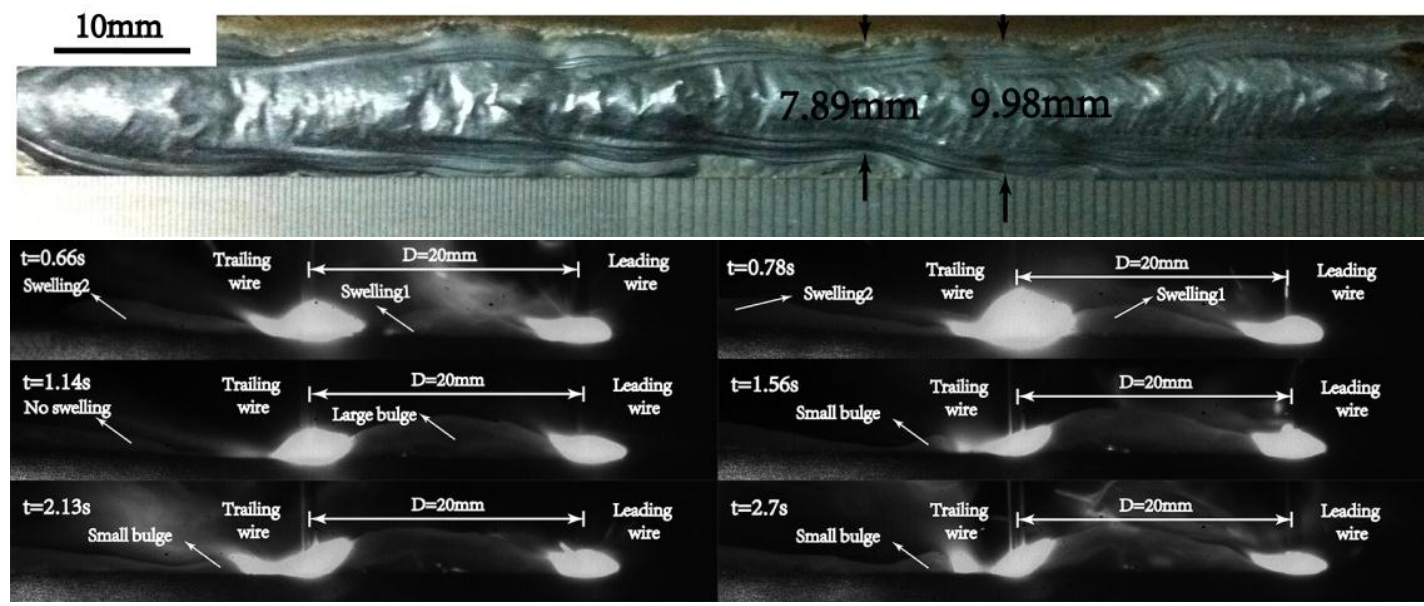

Fig.15 (A) Top view of the final weld bead, the trailing wire current is larger than the leading wire current; (B) High speed photographs of the weld pool in twin wire GMAW process.

\subsection{Comparison of simulation and experimental results}

In order to validate the simulations, the weld width, reinforcement, penetration, hump height and valley height are compared. The reasons that cause the differences of simulation and experimental results are discussed.

It can be seen in table 3 that the predicted results are in good agreement with those in the experiment in normal speed GMAW process. In high speed GMAW process, the weld width in simulation is close to that in experiment, there are large differences in the weld penetration, hump height and valley height between simulation and experiment. It is supposed that the arc pressure obtained from the empirical equation is higher than that in the actual experiment. Accurate prediction of arc pressure and heat input from the arc in high speed GMAW process is a future goal of the authors.

Table 3 Comparison of predicted and experimental weld pool geometry parameters in normal speed GMAW process

\begin{tabular}{cccc}
\hline Reference & Weld width $(\mathrm{mm})$ & Weld reinforcement $(\mathrm{mm})$ & Weld penetration $(\mathrm{mm})$ \\
\hline Predicted & 9.91 & 3.21 & 3.33 \\
Experimental & 10.36 & 2.96 & 3.19 \\
Difference & $4.3 \%$ & $8.4 \%$ & $4.4 \%$ \\
\hline
\end{tabular}

Table 4 Comparison of predicted and experimental weld pool geometry parameters in high speed GMAW process

\begin{tabular}{ccccc}
\hline Reference & Weld width $(\mathrm{mm})$ & Weld penetration $(\mathrm{mm})$ & Hump height $(\mathrm{mm})$ & Valley height $(\mathrm{mm})$ \\
\hline Predicted & 5.96 & 1.98 & 5.76 & 1.77 \\
Experimental & 6.55 & 1.69 & 2.38 & 0.90 \\
\hline
\end{tabular}




\section{Conclusions}

Based in the simulation and experimental results, the following conclusions can be drawn:

(1) The formation of gouged region in high speed GMAW process can increase the velocity of the backward fluid flow.

(2) In normal speed GMAW process, a clockwise circulation and a backward fluid flow pattern exist in the weld pool behind the arc. In high speed GMAW process, the molten metal flows to the trailing of the weld pool, but the backfilling of the front part of the weld pool does not occur.

(3) In normal speed GMAW process, due to the outward flow pattern, the difference of weld width in the welding direction is small. In high speed GMAW process, as a large amount of molten metal accumulated at the back of the weld pool, the variation of the weld width is large, which causes the large variation of the capillary pressure of the liquid channel in the welding direction.

(4) Three main factors are responsible to the humping formation: the high momentum of the backward fluid flow, the large variation of the capillary pressure of the liquid channel in the welding direction, and the capillary instability. These factors are suppressed in twin wire GMAW weld pool, so the humping disappears.

(5) In order to obtain sound weld bead, the trailing wire current should not be larger than the leading wire current.

\section{Acknowledgments}

This research effort was supported by the National Science Foundation of china [Grant Number: 51275299 and 51504152].

\section{Reference}

[1] Nguyen T C, Weckman D C, Johnson D A, et al. The humping phenomenon during high speed gas metal arc welding[J]. Science \& Technology of Welding \& Joining, 2005, 10(4):447-459(13).

[2] Bradstreet B J. Effect of surface tension and metal flow on weld bead formation[J]. Welding Journal, 1968, 47(6): 314s-322s.

[3] Nguyen T C, Weckman D C, Johnson D A. Predicting onset of high speed gas metal arc weld bead defects using dimensional analysis techniques[J]. Science \& Technology of Welding \& Joining, 2007, 12(7):634-648.

[4] Cho M H, Farson D F. Understanding bead hump formation in gas metal arc welding using a numerical simulation[J]. Metallurgical and materials transactions B, 2007, 38(2): 305-319.

[5] Chen J, Wu C S. Numerical analysis of forming mechanism of hump bead in high speed GMAW[J]. Welding in the World, 2010, 54(9-10): R286-R291.

[6] Amara E H, Fabbro R. Modeling of humps formation during deep-penetration laser welding[J]. Applied 
Physics A Materials Science \& Processing, 2010, 101(1):111-116.

[7] Berger P, Hügel H, Hess A, et al. Understanding of Humping Based on Conservation of Volume Flow[J]. Physics Procedia, 2011, 12:232-240.

[8] Wei P S, Chuang K C, Debroy T, et al. Scaling of spiking and humping in keyhole welding[J]. Journal of Physics D Applied Physics, 2011, 44(24):245501-245511(11).

[9] Meng X, Qin G, Zou Z. Investigation of humping defect in high speed gas tungsten arc welding by numerical modelling[J]. Materials and Design, 2016, 94:69-78.

[10] Choi H W, Farson D F, Cho M H. Using a Hybrid Laser Plus GMAW Process for Controlling the Bead Humping Defect[J]. Welding Journal, 2006, 85(8):174s-179s.

[11] Zhou J, Tsai H L. Modeling of transport phenomena in hybrid laser-MIG keyhole welding[J]. International Journal of Heat \& Mass Transfer, 2008, 51(17-18):4353-4366.

[12] Wu C S, Hu Z H, Zhong L M. Prevention of humping bead associated with high welding speed by double-electrode gas metal arc welding[J]. International Journal of Advanced Manufacturing Technology, 2012, 63(5-8):573-581.

[13] Dongsheng $\mathrm{Wu}$, Xueming Hua, Dingjian Ye, et al. Understanding of the weld pool convection in twin-wire GMAW process[J]. International Journal of Advanced Manufacturing Technology, 2016:1-9.

[14] Li Y, Wu C S, Wang L, et al. Analysis of additional electromagnetic force for mitigating the humping bead in high-speed gas metal arc welding[J]. Journal of Materials Processing Technology, 2015, 229:207-215.

[15] Wang L, Wu C S, Gao J Q. Suppression of humping bead in high speed GMAW with external magnetic field[J]. Science \& Technology of Welding \& Joining, 2016, 21(2):131-139.

[16] Meng Q G, Fang H Y, Yang J G, et al. Analysis of temperature and stress field in Al alloy's twin wire welding[J]. Theoretical \& Applied Fracture Mechanics, 2005, 44(2): 178-186.

[17] Hu J, Guo H, Tsai H L. Weld pool dynamics and the formation of ripples in 3D gas metal arc welding[J]. International Journal of Heat \& Mass Transfer, 2008, 51(9-10):2537-2552.

[18] Wang Y, Tsai H L. Effects of surface active elements on weld pool fluid flow and weld penetration in gas metal arc welding[J]. Metallurgical \& Materials Transactions B, 2001, 32(3):501-515.

[19] Min H C, Yong C L, Farson D. Simulation of weld pool dynamics in the stationary pulsed gas metal arc welding process and final weld shape[J]. Welding Journal, 2006, 85:271s-283s.

[20] Wang Y, Tsai H L. Impingement of filler droplets and weld pool dynamics during gas metal arc welding process[J]. International Journal of Heat \& Mass Transfer, 2001, 44(11):2067-2080.

[21] Cao Z, Yang Z, Chen X L. Three-dimensional simulation of transient GMA weld pool with free surface[J]. Welding Journal, 2004, 83: 169-S.

[22] Gratzke U, Kapadia P D, Dowden J, et al. Theoretical approach to the humping phenomenon in welding processes[J]. Journal of Physics D Applied Physics, 2000, 25(11):1640-1647. 